
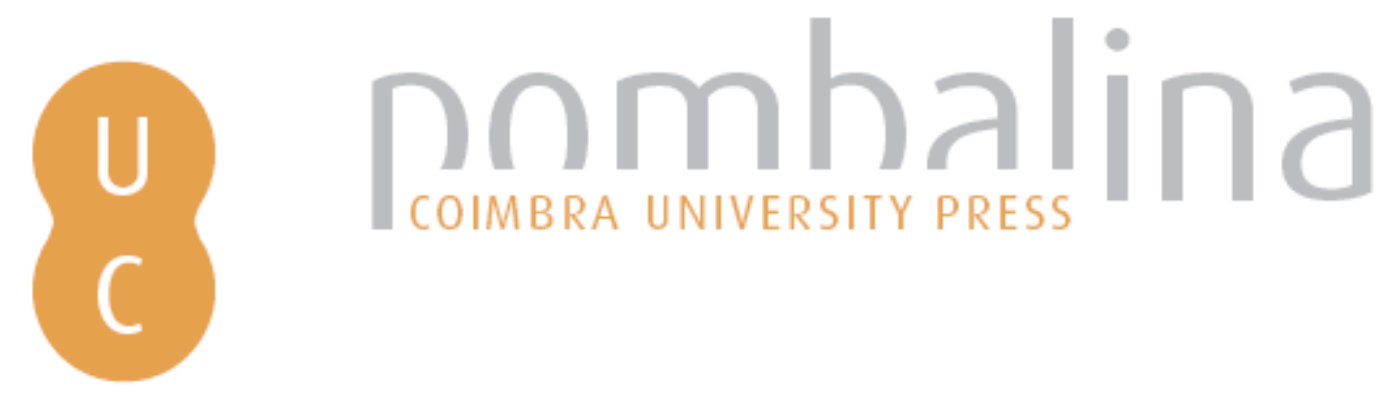

\title{
O conflito ateniense entre Atena e Posêidon em Troianas e Erecteu de Eurípides
}

\author{
Autor(es): Werner, Christian \\ Publicado por: Imprensa da Universidade de Coimbra \\ URL \\ persistente: URI:http://hdl.handle.net/10316.2/45155 \\ DOI: $\quad$ DOI:https://doi.org/10.14195/978-989-26-1679-7_13
}

Accessed : $\quad$ 26-Apr-2023 12:59:36

A navegação consulta e descarregamento dos títulos inseridos nas Bibliotecas Digitais UC Digitalis, UC Pombalina e UC Impactum, pressupõem a aceitação plena e sem reservas dos Termos e Condições de Uso destas Bibliotecas Digitais, disponíveis em https://digitalis.uc.pt/pt-pt/termos.

Conforme exposto nos referidos Termos e Condições de Uso, o descarregamento de títulos de acesso restrito requer uma licença válida de autorização devendo o utilizador aceder ao(s) documento(s) a partir de um endereço de IP da instituição detentora da supramencionada licença.

Ao utilizador é apenas permitido o descarregamento para uso pessoal, pelo que o emprego do(s) título(s) descarregado(s) para outro fim, designadamente comercial, carece de autorização do respetivo autor ou editor da obra.

Na medida em que todas as obras da UC Digitalis se encontram protegidas pelo Código do Direito de Autor e Direitos Conexos e demais legislação aplicável, toda a cópia, parcial ou total, deste documento, nos casos em que é legalmente admitida, deverá conter ou fazer-se acompanhar por este aviso.

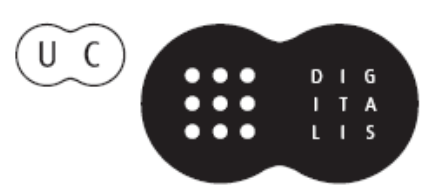



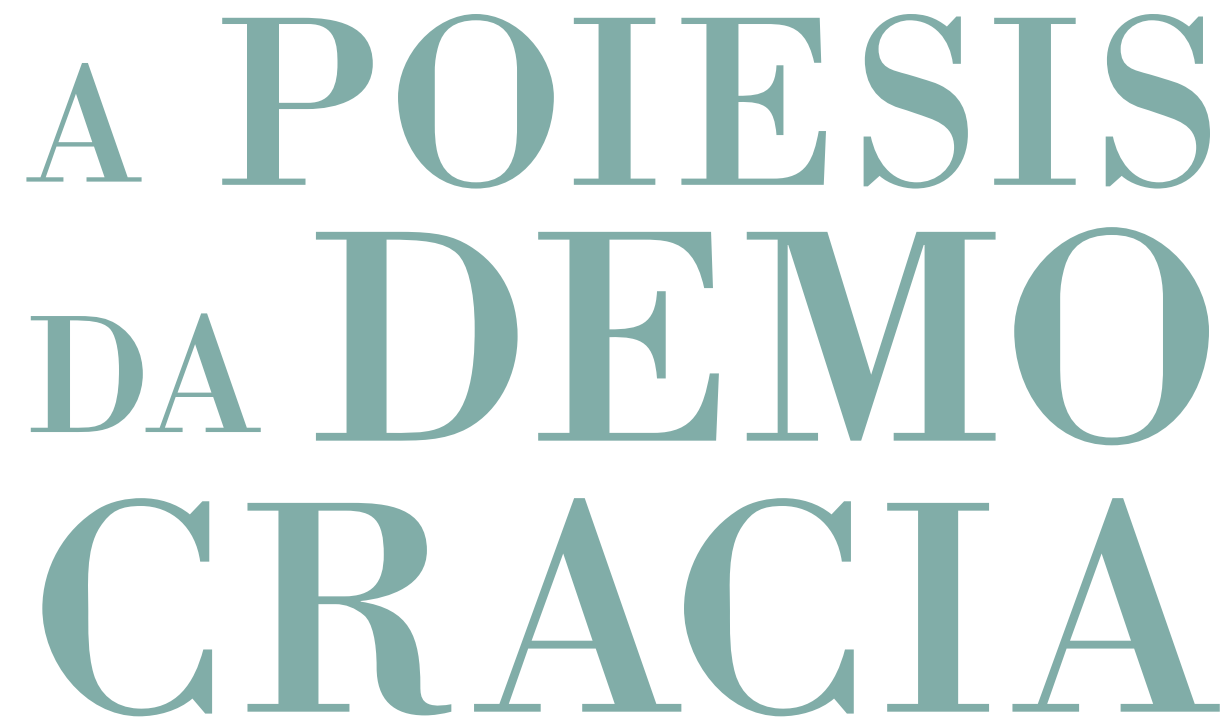

G

Breno Battistin Sebastiani, Delfim Leão,

Lugia Sano, Martinho Soares, Christian Werner

\section{CoimbraCompanions}




\title{
O conflito ateniense
}

entre Atena e Posêidon em troianas e ERECTEU DE EURÍPIDES

\section{The Athenian Dispute}

\author{
BETWEEN ATHENA AND POSEIDON IN \\ EURIPIDES' TROJAN WOMEN AND ERECHTHEUS
}

Christian Werner

Universidade de São Paulo

ORCID | 0000-0001-8948-6825 


\section{Resumo}

Para se discutir as relações entre democracia e politeísmo na Atenas do século $\mathrm{V}$, investiga-se de que forma dois temas tradicionais interligados, o conflito entre deuses e a salvação ou destruição de uma polis por seu deus tutelar, subjazem a diferentes configurações imaginárias de Atena e Posêidon nas tragédias Erecteu e Troianas de Eurípides. O conflito entre esses deuses pelo domínio sobre Atenas adquiriu contornos particulares, sobretudo quando a frota ateniense passou a garantir o poder militar e econômico da cidade e quando a Guerra do Peloponeso trouxe o inimigo de volta à Ática. Nessas tragédias de Eurípides, a decisão de destruir ou não uma coletividade política no contexto de uma conquista violenta depende da negociação entre os deuses (Troianas) ou entre um deus e uma casa real (Erecteu). Mais especificamente, levando-se em conta que a história do "Saque de Troia" (Ilioupersis) representada nas métopas norte do Pártenon ou bem lembra a cidade da destruição causada pelos persas ou bem a incentiva a punir aqueles que tiverem cometido uma injustiça, Troianas talvez também convide o público ateniense a pensar sobre o futuro da cidade no que diz respeito a seus deuses tutelares.

\section{Palavras-chave}

Eurípides, Atena, Posêidon, Troianas, Erecteu 


\section{Abstract}

In order to discuss the relationship between democracy and polytheism in Athens in the 5 th century $\mathrm{BC}$, this paper investigates how two traditional, intertwined themes - the conflict between gods and the destruction of a city by its tutelary god - are reflected in the representation of Athena and Poseidon in Euripides' Trojan Women and Erechtheus. The quarrel between these gods over Athens acquired specific contours during the 5th century as the Athenian fleet became the guarantor of the city's economic and military power and the Peloponnesian War brought the enemy back to Attica. In these Euripidean tragedies, the decision to destroy a political collectivity in the context of a violent conquest depends on a negotiation between gods (Trojan Women) or between a god and a royal family (Erechtheus). More specifically, given that the "Sack of Troy" (Ilioupersis) depicted in the north metopes of the Parthenon reminds the city of its destruction by the Persians or encourages it to punish those who commit a bybris, Trojan Women may also invite an Athenian audience to think about the future of their city regarding their tutelary gods.

\section{Keywords}

Euripides, Athena, Poseidon, Trojan Women, Erechtheus 


\section{INTRODUÇÃO ${ }^{1}$}

Já se defendeu que não há nenhuma relação exclusiva entre as práticas democráticas e as religiosas em Atenas, uma vez que essas últimas em nada se diferenciariam, quanto à sua essência, daquelas de outras poleis gregas. ${ }^{2}$ Algo semelhante já foi amiúde afirmado acerca da tragédia ática. Além da significativa presença de estrangeiros no teatro de Dioniso, ${ }^{3}$ tragediógrafos atenienses atuavam fora de Atenas e, sobretudo a partir do final do século $\mathrm{V}$, o teatro se tornou uma prática cada vez mais comum fora de Atenas, e a mobilidade dos profissionais ligados a ele aumentou de forma significativa, em particular a dos atores, que se tornaram verdadeiras celebridades. Nesse contexto, nas tragédias compostas em Atenas, referências diretas ou indiretas à democracia contemporânea seriam, no máximo, laterais em relação à performance trágica como um todo e um fenômeno, portanto, explicado apenas parcialmente pela matéria da tragédia ser o mundo heroico. De fato, encenações trágicas (e cômicas) são uma forma de mousike, mais especificamente, uma performance coral pública, que, por sua vez, é um fenômeno pan-helênico. ${ }^{4}$

1 O presente trabalho foi realizado com apoio do CNPq, Conselho Nacional de Desenvolvimento Científico e Tecnológico - Brasil. Todas as traduções são de minha autoria. A tradução das passagens de Troianas é de Werner 2004; o texto traduzido é o de Diggle 1981. Agradeço aos comentários e sugestões dos colegas nos eventos em São Paulo e Coimbra, em particular, Maria do Céu Fialho e Maria de Fátima Sousa e Silva.

2 Para uma crítica desse ponto de vista, cf. Osborne 2013.

3 Todas as datas nesse texto são a.C.

4 Sobre a leitura "política" versus "estética" ou "poética" da tragédia, a bibliografia é enorme; cf. síntese em Allan e Kelly 2013, esse resumido em Allan 2014. Representações trágicas fora de Atenas, cf. Csapo e Wilson 2015, com bibliografia suplementar. Roselli 2011 defende o helenocentrismo (em oposição ao atenocentrismo) do fenômeno teatral grego; no capítulo quatro desse livro, investiga a presença de estrangeiros nos festivais teatrais em 
Forçando um pouco o paralelismo, pode-se mencionar o Pártenon, construído na Acrópole nas décadas de 440 a 430, tendo em vista sobretudo um de seus marcos distintivos, o friso jônico que percorria toda a colunata da cela, parte do qual se encontra hoje no Museu Britânico. Sempre intrigou os pesquisadores a visão parcial que os visitantes do templo teriam desse conjunto notável a 10 metros do solo entre a cela e as colunatas sobre as quais ficavam os frontões. Também não há consenso sobre o que representa o conjunto de várias dezenas de imagens esculpidas no friso. A interpretação mais aceita vê na proposta do conjunto uma visada democrática, mas também já se defendeu que nela se destacaria a memória de um mito fundador de Atenas, o sacrifício da filha de Erecteu, que antecede a vitória sobre o exército de Eumolpo. Tal mito seria independente da politeia de Atenas, mas não conhecemos nenhuma representação dele anterior ao Erecteu de Eurípides, o que colabora para enfraquecer a hipótese. ${ }^{5}$

Temos assim três fenômenos culturais fundamentais em Atenas cujas relações com as práticas democráticas vigentes nos séculos V e IV são difíceis de serem precisadas. Por meio de duas tragédias de Eurípides, Troianas e Erecteu, vou explorar um ou dois mitos centrais para a discussão das formas como os atenienses se percebiam no século V ou, vale dizer, defendiam sua politeia, e mostrar que as configurações particulares que recebem nesses textos dependeram, sim, de práticas democráticas, em particular, da valorização do discurso e do debate público. Meu objetivo, portanto, não é novo: explorar a interdependência entre práticas políticas e culturais no ambiente democrático ateniense. ${ }^{6}$

\footnotetext{
Atenas. Hanink 2014 mostra as razões por que, na Atenas da segunda metade do século IV, procurou-se reforçar a ideia de uma raiz ateniense da tragédia.

5 Sobre friso "democrático": Osborne 2010: 289-322, entre outros. Acerca do friso "mítico": Connelly 1996, tese retomada por Connelly 2014, criticada por Cropp 2014. Para um resumo das interpretações mais significativas, cf. Shear 2016: 401-4. Em vista do escopo e do tamanho máximo deste capítulo, a discussão da documentação material reduziu-se ao mínimo. A principal razão para sua inclusão é embasar a afirmação de que os temas míticos investigados nas duas tragédias eram centrais no imaginário ateniense.

6 Para aprofundar a discussão e não incluir momentos históricos completamente diferentes daquele ao qual pertence a encenação das duas tragédias aqui tratadas, deixei de lado outros dramas nos quais os mitos em questão são relevantes, em particular, como observaram, respectivamente, Maria do Céu Fialho e Maria de Fátima Sousa e Silva, Édipo em Colono (por conta de seu $1^{\circ}$ estásimo) e Íon.
} 
Troianas inicia com um diálogo entre Atena e Posêidon no qual a deusa expressa o desejo de se vingar dos gregos por meio de um naufrágio da esquadra que retorna, pois esses foram condescendentes com Ájax, autor de um sacrilégio no templo troiano de Atena. Toda a ação subsequente gravita em torno de Hécuba, que nunca sai de cena e recebe notícias cada vez mais devastadoras das personagens que, uma após a outra, entram em cena e, com exceção de Taltíbio, dela saem para não mais voltar. Solidariedade constante a rainha recebe do coro de cativas troianas, que amplificam, por meio de seus cantos, diversos temas e imagens que perpassam a tragédia, e também, até certo ponto, de Taltíbio, o principal elo entre o acampamento grego e as mulheres que se preparam para enfrentar a escravidão em cidades gregas. O único líder grego que entra em cena é Menelau, testemunha ou juiz do julgamento de Helena. As duas desgraças que fecham o drama são a entrada em cena do cadáver de Astíanax, enterrado pela avó, e a destruição final da cidade por meio de um incêndio.

Uma opinião comum sobre a representação e a função dos deuses no drama é que eles estariam distantes das troianas, ou seja, apesar de Posêidon auxiliar Atena a punir os gregos por meio de um naufrágio (Tr. 73-94), essa demonstração de poder não seria feita com vistas a punir crimes de guerra, reforçando supostas leis não escritas, mas para satisfazer o orgulho ferido dos próprios deuses, em especial, o de Atena.7 Quanto às troianas, defendeu-se que sua raiva contra os deuses antropormofizados cresceria - no limite, chegando à descrença em sua existência - porque lhes ficaria cada vez mais clara a ingratidão dos deuses em relação ao passado da cidade e de seus habitantes. ${ }^{8}$ Ver-se-á que essas leituras são redutoras à medida que não levam em consideração a maior ou menor aproximação que a plateia do drama poderia estabelecer entre o que vê em cena e seu próprio tempo.

7 Cf. Conacher 1967: 137 e Poole 1976: 264.

8 Cf. Lefkowitz 1989 e Lee 1976: 154. Para a defesa da relevante distância que separa os deuses antropomorfizados do divino em sua manifestação não-mítica no teatro de Eurípides, cf. Pucci 2016. 
O enredo de Erecteu pode ser reconstruído em linhas gerais graças a trechos transmitidos de forma indireta ${ }^{9}$ e a um longo fragmento papiráceo. A ação central é a batalha dos atenienses, liderados pelo rei Erecteu, contra o exército invasor trácio comandado por Eumolpo, que busca vingar seu pai Posêidon por esse ter perdido Atenas para Atena. ${ }^{10}$ Um oráculo determina o sacrifício de uma das filhas do rei autóctone, aceito prontamente pela sua mãe, Praxítea. ${ }^{11}$ Dessa personagem nos chegaram trechos de um longo discurso, pleno de tópicas da oração fúnebre, reproduzidos pelo patriótico Contra Leócrates de Licurgo. Realizado o sacrifício, a batalha é ganha pelos atenienses, mas nela morre Erecteu, atingido por Posêidon, ação concomitante ao suicídio das outras duas filhas do rei, um sacrifício simbólico junto com o da irmã. O drama termina com uma ação de Atena, a interrupção de um terremoto provocado por Posêidon, e um discurso que contém etiologias referentes aos mortos e ao culto da deusa e do próprio rei como PosêidonErecteu na Acrópole. ${ }^{12}$

Faz-se notar em Erecteu e, menos obviamente, em Troianas a estreita relação imaginária entre Atenas e a deusa Atena, a qual já é mencionada brevemente nos dois poemas homéricos canônicos. ${ }^{13}$ Dois temas tradicionais permeiam essa relação: o conflito entre deuses, qual seja, aquele entre Atena e Posêidon por Atenas, e a salvação de uma polis por seu deus tutelar. ${ }^{14}$ Para além do plano estritamente mítico, após o núcleo urbano de Atenas ser arrasado pelos persas em 480, seu ressurgimento, na sequência

9 Sobretudo em Contra Leócrates (330) de Licurgo, cuja família proclamava ser descendente de Erecteu (Worthington, Cooper \& Harris 2001: 153-57).

10 A tragédia de Eurípides é a primeira representação supérstite dessa façanha de Erecteu. Acerca da relação possível entre o Eumolpo euripidiano e o homônimo mencionado no Hino a Deméter, cf. Richardson 1974: 197-98. A história de que Íon derrotou uma invasão trácia é possivelmente do século VI (Sonnino 2010: 45-62). Para um resumo das questões, cf. Parker 1987: 203-4.

11 Pucci 2016: 100-3 analisa as premissas e as consequências dessa prontidão.

12 Acerca de Erecteu e o contexto de citação dos fragmentos mais longos em Contra Leócrates: Collard et al. 1995, Calame 2011 e Hanink 2014: 25-59. Sobre Erecteu e a tradição do logos epitaphios: Sonnino 2010: 36-42.

13 As referências diretas são: Hom. Il. 2. 546-9; Od. 3. 278-307, 7. 80 e 11. 323. Trata-se de passagens que sempre de novo, na antiguidade e modernidade, foram consideradas interpolações.

14 Acerca desse tema tradicional, cf. Parker 1987: 199-200. 
da vitória em Salamina, foi marcado no imaginário pelo renascimento do broto da oliveira sagrada mantida na Acrópole e que fora queimada pelo fogo inimigo. ${ }^{15}$ Essa história revela, in nuce, o quanto os mitos em questão sustentam a imagem que os atenienses cultivavam acerca de sua cidade.

Troianas também fala de uma cidade que cultuava Atena e cujos templos são arrasados em uma guerra. Levando-se em conta que a história do "saque de Troia" representada nas métopas norte do Pártenon talvez lembrasse os atenienses da destruição de sua cidade pelos persas, ${ }^{16}$ um dos objetivos de meu texto é discutir que perspectiva Troianas, que encena um momento da destruição de Troia, coloca ao público ateniense em vista da superioridade tradicional de Atenas, celebrada sobretudo a partir da fundação da Liga de Delos e manifestada em sua política imperialista: por um lado, são Atena e Posêidon, os deuses tutelares de Atenas, que decidem destruir o exército invasor heleno no início dessa tragédia de 415; por outro lado, nenhuma continuidade política resta à comunidade troiana, totalmente aniquilada. Atenas, portanto, não pode ser simplesmente aproximada nem dos troianos nem dos gregos. Pergunta-se, assim, se a imagem elogiosa de Atenas evocada na tragédia, que, por sua vez, embasa a ideologia democrática ainda preponderante em 415, é relativizada por outros elementos do drama, em particular, pelo seu prólogo, ou se Troianas de forma alguma sugere ao público ateniense que o aniquilamento poderia ser o destino de sua cidade, caso se aceite que as diferenças entre Troia e Atenas seriam bem mais acentuadas no desenvolvimento do drama que as semelhanças. ${ }^{17}$

15 Sobre a história do broto: Heródoto 8, 55 e Bowie 2012: 277.

16 Cf. Ferrari 2000: 139-42, para quem a destruição de Troia representada no Pártenon prefigurava a destruição de Atenas pelos persas, em especial, a do velho templo de Atena Políade. As métopas do lado norte, porém, estão bastante danificadas e qualquer interpretação do conjunto é apenas aproximada. Assim, cf. Shear 2016: 110-12 para uma defesa da interpretação canônica, a saber, a aproximação entre os gregos representados nas métopas e os atenienses vitoriosos sobre os persas: tal interpretação, que tem a vantagem de produzir um paralelo entre as quatro batalhas representadas no conjunto das métopas, baseia-se no suposto papel dos deuses na narrativa (eles apoiariam a punição da hybris dos troianos pelos gregos) e na suposta ausência dos crimes gregos no conjunto (não sabemos, porém, o que estava representado em boa parte das métopas)

17 Essa segunda hipótese encontraria apoio na forma de se ler a tragédia grega defendida por Allan \& Kelly 2013. 
A ligação entre Atena e Atenas pressupõe um elemento político. São duas as posições antagônicas difíceis de serem sustentadas em seu radicalismo: negar ou subestimar o viés político da tragédia ateniense ou conferir-lhe exclusividade. Isso ocorre, entre outras razões, por nossas informações deficientes acerca da recepção dos dramas no século V e também por discordâncias na definição do que seja "político". ${ }^{18}$ Assim, em Troianas, a exploração da temática da guerra e de suas consequências por certo é saliente na superfície da ação dramática, mas, em que pese a guerra entre Atenas e Esparta dominar o cenário político e a vida em Atenas em 415, disso não advém, forçosamente, o viés antibélico que costuma predominar em suas montagens modernas, ainda que se coloque os trechos em trímetros, sobretudo as rheseis, em segundo plano com o intuito de reforçar o impacto do caráter experimental da música euripidiana ou de identificar e destacar, na economia dramática, como que a estrutura de um oratório, um longo lamento feminino que se revela nas inúmeras partes cantadas. ${ }^{19}$

Já o prólogo de Troianas possibilita uma recepção política do drama por meio do modo como Eurípides trata dos deuses e do divino, sobretudo ao se levar em conta o paralelo com a disputa entre Posêidon e Atena pela supremacia sobre Atenas representada em Erecteu, tragédia que contempla uma história que foi representada no frontão oeste do Pártenon, aquele que primeiro se revela ao visitante que cruza os Propileus. ${ }^{20}$ Trata-se, portanto, de uma problema amplo e complexo, que depende não só da polêmica acerca do modo como o público ateniense aproxima ou afasta o mundo mítico representado em cena de seu próprio mundo contemporâneo, mas também de estudos sobre a religiosidade tradicional na Atenas do século

18 Para definição de "político", cf. Carter 2007: 1-89 e também Pucci 2016: 103-12.

19 Sobre o viés antibélico - no geral ou, em particular, em relação à Guerra do Peloponeso (ou, ainda mais em particular, ao massacre em Melos) - como central no drama, cf. entre outros, Kovacs 1997. Esse viés, por certo, domina performances modernas da tragédia. Para uma discussão dessa questão a partir do drama Les Troyennes, de Sartre, cf. Loraux 1999: 1-27 e igualmente Werner 2011, que contrapõe o drama de Eurípides ao filme de Cacoyannis, de 1972. Acerca do lamento feminino em Troianas: Loraux 1999, Sutter 2003 e Wohl 2015: $39-62$.

20 Acerca do caráter aparentemente extraordinário, no que diz respeito à sua representação plástica, do conflito entre Atena e Posêidon narrado no frontão oeste, cf. Shear 2016: 112-16. 
$\mathrm{V}$ e sobre o modo como essa é representada na poesia e discutida por intelectuais coetâneos. ${ }^{21}$

\section{Posêtdon e as muralhas de Troia: O Prólogo de Troianas 22}

A especificidade desse prólogo, dentre aqueles das tragédias restantes de Eurípides, é evidente. Embora o monólogo de Posêidon, que contém informações retrospectivas e prospectivas, seja típico desses prólogos, ${ }^{23}$ no diálogo que segue, o futuro desvelado por Atena e Posêidon aponta para um tempo posterior ao fim do drama, ou seja, ambos se comportam, de fato, como deuses ex machina, cuja aparição se dá no final de uma tragédia. Em Troianas, além disso, a ação que planejam não diz respeito diretamente aos agentes do drama (as cativas de guerra), mas a seus algozes, os gregos.

Isso torna ainda mais significativa a questão de por que os deuses anunciam um acontecimento futuro para além do tempo dramatizado. Uma resposta possível é que a tragédia não tem um final propriamente dito, com o que seria acentuado o sofrimento sem fim das troianas, às quais não é dado nem mesmo o consolo de saber que parte do inimigo será aniquilada. ${ }^{24}$ Pelo contrário, todas intuem que até Helena, a inimiga mais odiada, será poupada por seu marido. Corolário disso é que o prólogo seria estruturalmente independente do restante da tragédia. ${ }^{25}$

21 Para o problema da religião no teatro, cf. Parker 2005, especialmente o capítulo sete, e Sourvinou-Inwood 2003. Para uma defesa do caráter "iluminista" (enlighted) da poética euripidiana, cf. Pucci 2016.

22 Uma versão bastante resumida e que, em alguns pontos, se diferencia um pouco do que discuto abaixo acerca do prólogo de Troianas, nesta seção e na última, encontra-se em Werner 2004: xxxviii-xli e 2011: 133-34.

23 Cf. Lloyd 2007: 295-96.

24 Essa é a interpretação de Dunn 1993. Repare-se que Cassandra prevê a morte de Agamêmnon e a desgraça que atingirá sua linhagem, mas seus ouvintes a ignoram.

25 A consequência dessa "anomalia estrutural", para Wohl (2015: 42-49), é o espectador sair de sua passividade de admirador do belo ao modo de Zeus e Ganimedes e de sofredor compassivo ao modo de Taltíbio: "to really do justice to this suffering, the prologue suggests, it is not enough to weep" (p. 48). 
Posêidon, no monólogo que abre a tragédia, despede-se de sua cidade. ${ }^{26}$ Quanto a Atena, a deusa vem anunciar uma vingança, ação divina tradicional no universo mítico. Por que dois deuses pan-helênicos, que têm forte apelo cultual no contexto ateniense, se encontram em cena, algo que parece inédito em Eurípides? ${ }^{27}$

Duas funções dramáticas do monólogo de Posêidon se destacam: fornecer coordenadas temporais e espaciais aos espectadores e sublinhar o aniquilamento de Troia. Seu discurso inicia a separação entre o deus e a cidade que lhe é cara:28 "nunca de meu espírito, / contra a cidade, partiu

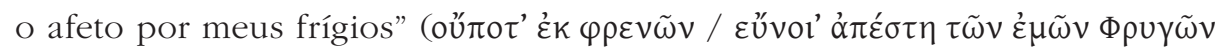
$\pi o ́ \lambda \varepsilon l, \operatorname{Tr}$. 6-7). A sonoridade e a estrutura sintática ambígua desta frase reforçam a proximidade entre o deus e os troianos, uma inovação de Eurípides. ${ }^{29}$

26 Trata-se de uma ação homóloga à de Apolo no prólogo de Alceste, que abandona a casa de Admeto para evitar o contato com a impureza da morte, um miasma (E. Alc. 22-23; Parker 2007: 57).

27 Atena e Posêidon formam uma dupla bastante diferente do par Apolo e Morte do prólogo de Alceste; para uma diferença do tom - de (im)polidez - no diálogo entre esses dois pares de deuses, cf. Lloyd 2009. Atena e Posêidon fazem parte dos doze olímpicos, grupo que, em alguns lugares, entre eles, Atenas, passou a receber culto a partir do final do século VI (Parker 2011: 71). Os dois deuses são bastante atuantes na tradição épicoheroica, a matriz central da tragédia ática.

28 Acerca da relação especial entre um deus e uma cidade, cf. a síntese de Parker 2011: 86-87: "Greeks... often spoke in terms of the especial love of particular gods for particular cities. The role of 'chief god' or 'special god' was not acknowledged explicitly other than through the language of a god's love for a place, and there is no epithet that indicates it; chief gods are often called 'of the city' (Polias) or 'protector of the city' (Poliouchos)... But in many cities the phenomenon is undeniable: the roles of Athena at Athens and of Hera in Argos, Samos and in many places in Magna Graecia are the model cases".

29 A frase pode ser interpretada, quanto à sintaxe, de mais de um modo. A leitura mais imediata seria a seguinte: "o afeto nunca partiu de meu espírito para (o mal d)a [= contra a] cidade dos frígios". Considera-se ró $\lambda \varepsilon$ um dativo de desvantagem e lê-se $\tau \tilde{\omega} v \dot{\varepsilon} \mu \tilde{\omega} v$ com

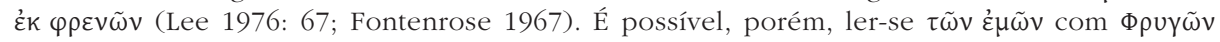
(Wilson 1968). $\tau \tilde{\omega} v \dot{\varepsilon} \mu \tilde{\omega} v$, por outro lado, pode muito bem ser uma construção apo koinou (Biehl 1989: 101); acrescentemos que essa hipótese se fortalece caso tivermos em vista a aliteração entre દ̇k $\varphi \rho \varepsilon v \tilde{\omega} v$ e $\Phi \rho v \gamma \tilde{\omega} v$. Assim, o que o público poderia ouvir é "nunca de meu espírito, contra a cidade de meus frígios, o afeto partiu". O mesmo se dá se considerarmos

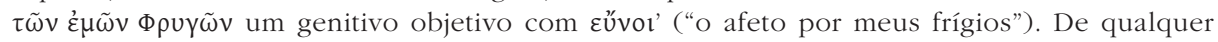
modo, além de enfatizar-se a relação entre o deus e os troianos, da mesma forma destacase a união entre o deus e sua cidade devido às posições enfáticas, nas pontas dos respectivos

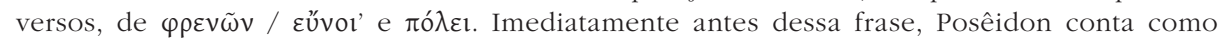
ele e Apolo construíram a muralha em torno de Troia (Tr. 4-6).

Em Homero (Il. 21. 435-68), Posêidon critica Apolo por querer lutar contra ele, já que os dois sofreram pelos troianos: ao passo que Apolo apascentou um rebanho bovino, Posêidon 
A fala de Posêidon não sugere um desejo de vingança contra os gregos, pois esses não cometeram nenhum sacrilégio específico contra ele. ${ }^{30}$ Todavia, quando o deus menciona que "ao pé da base do altar ( $\pi \rho$ ò $\delta \dot{\varepsilon} \kappa \rho \eta \pi i ́ \delta \omega v$

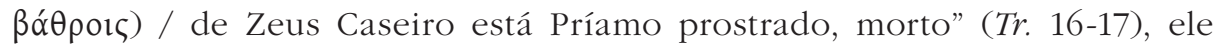
está se referindo a um conjunto de ações, a tradicional tomada de Troia, que, na Atenas do século V, em representações literárias e imagéticas, era tido como exemplo mítico de bybris. ${ }^{31}$

O termo bathron, traduzido por altar, ${ }^{32}$ reaparece no final do monólogo, quando Posêidon diz que, da cidade, nada mais se encontra sobre seus fundamentos (en bathrois, Tr. 47). É comum um altar ter uma vocação inaugural, ${ }^{33}$ de sorte que, nos versos 16 a 17, ao ser referido como ponto final da história da cidade por conta do nexo com o cadáver do rei, cria-se uma tensão. Posêidon, porém, demonstra resignação, não raiva contra os gregos. ${ }^{34} \mathrm{O}$ deus lamenta o fim funesto da cidade e anuncia sua partida temendo o contato com algo impuro, o que, em contextos semelhantes, é próprio do imaginário grego. ${ }^{35}$

construiu uma muralha para que a cidade se tornasse inexpugnável (arrektos, 447). A ênfase do deus, porém, é que não receberam paga de Laomédon pelo serviço, de sorte que não haveria razão para Apolo defender a cidade. Na sequência, Apolo desiste de lutar contra Posêidon: segundo ele, por não valer a pena lutar pelos frágeis mortais; segundo a voz de Homero, por respeitar (aideomai) o irmão do pai. Vale notar que, em Hom. Il. 7. 452-53, Posêidon diz que os dois construíram a muralha. Em E. Andr. 1009-18, Apolo é explícita, Posêidon, implicitamente referido como construtor da muralha, aludindo-se, na sequência, à ajuda que ambos forneceram aos dois exércitos, ou seja, a versão iliádica canônica.

30 Cf. Kovacs 1983: 335-36.

31 Cf. Ferrari 2000. A morte de Príamo costuma ser representada em textos poéticos do século V como um crime punido por Apolo (Allan 2000: 26-28).

32 Para esse sentido de bathron, cf. E. HF 715 e S. Ant. 854.

33 Cf. Detienne \& Sissa 1990: 221.

34 Cf. Kovacs 1983: 335-36.

35 Sobre o receio de Posêidon, cf. Scodel 1980: 67 e Harder 1993: 9; deuses e a morte, cf. Parker 1997: 154, n. 42. 
CHRISTIAN WERNER

\section{Atena e Posêidon disputam Atenas: ERecteu E A Primeira oliveira}

Bathron, em um contexto cívico, evoca, no discurso trágico, a ligação da cidade com a terra ${ }^{36}$ e aponta para a integridade da instituição ligada ao espaço em questão, pela qual zelam deuses e homens. Em Erecteu, o termo aparece em dois discursos que, pela reconstituição permitida pelos fragmentos supérstites, são fundamentais na economia do drama. Diz Praxítea (TrGF 360, 43-49 Kannicht):

Quanto àquilo cuja maior parte é do coletivo,

ninguém, contra a vontade de minha alma,

jogará fora as vetustas leis dos ancestrais; ${ }^{37}$

nem ao invés da oliveira e da Górgona de ouro ${ }^{38}$

fincará o reto tridente nos fundamentos da cidade (en poleos bathrois)

Eumolpo, nem o exército trácio a cingirá

com coroas, nem Palas de forma alguma não será honrada.

Essa passagem faz parte da tentativa da rainha de convencer Erecteu a aceitar o sacrifício da filha mais velha. ${ }^{39}$ Ela menciona a existência de algo que é estável na cidade, ligado à tradição dos ancestrais e ao culto da deusa políade: trata-se da "integridade sagrada da cidade". ${ }^{40}$

Posêidon (evocado pelo "reto tridente") ${ }^{41}$ auxilia o invasor, mas não é o sacrifício da filha de Erecteu e, sim, Atena quem garante a permanência da cidade. ${ }^{42}$ Ao passo que Posêidon é responsável pelo discurso do prólogo, do

36 Cf., por exemplo, E. Supp. 1198 e o comentário de Sonnino 2010: 286. Em E. IA 705 e, sobretudo, $P h .982$, a referência parece ser a um fundamento sagrado; cf. também S. $A j$. 134-35. O mesmo vale, mutatis mutandis, para os fundamentos de um oikos; cf. S. Aj. 85960 (patroion hestias bathron).

37 Acerca desse verso, cf. Sonnino 2010: 284.

38 Como nota Sonnino 2010: 284-86, referência a dois monumentos do culto a Atena na Acrópole: a oliveira sagrada e uma parte da estátua de Atena que se encontrava no interior do Pártenon desde 438/7.

39 Situação dramática defendida pela maioria dos intérpretes; cf., entre outros, Kamerbeek 1991: 114, Collard, Cropp \& Lee 1995: 178 e Sonnino 2010: 249. Como é a mãe quem defende o sacrifício da filha, não se tem o típico "sacrificio voluntário" de outras tragédias euripidianas, cf. Silva 2005: 125-66.

40 A expressão é de Collard, Cropp \& Lee 1995: 181, ao comentarem "en poleos bathrois".

41 Cf. Sonnino 2010: 286.

42 Cf. Pucci 2016: 100-2, para quem esse elemento, em conjunto com a morte das outras duas irmãs e do pai, compõem a crítica "under cover" de Eurípides à ação mítica. 
qual não restou quase nada, ${ }^{43}$ Atena, no êxodo do drama, exige a interrupção do terremoto iniciado pelo seu colérico tio contra o palácio de Erecteu, cuja morte em batalha acabara de ser anunciada aos atenienses, e proclama uma série de etiologias cultuais (TrGF 370, 95-97 Kannicht): "Para ti, que endireitaste os fundamentos (exanorthosas bathrois) desta cidade, ${ }^{44} /$ concedo-te fazer sacrifícios preliminares, em meus altares, / para a cidade, sendo designada sacerdotisa". Atena dirige-se à rainha e faz dela a primeira sacerdotisa de Atena Políade. Repare-se que o verbo que acompanha bathra é metafórico, por um lado, mas, por outro, evoca as próprias muralhas protetoras da cidade, que podem ser (re)erguidas ou aniquiladas.

Tem-se, portanto, um exemplo da representação de um deus que reivindica para si, em detrimento de outro, os fundamentos de uma cidade. Em Troianas, por sua vez, trata-se de uma cidade que não existe mais, porém, do ponto de vista de Posêidon, representado como deus tutelar pela sua relação com a muralha da cidade e com seus habitantes, a situação não deixa de ser, no mínimo, parcialmente homóloga àquela de Erecteu: Posêidon reivindica a cidade como sua em relação às deusas que a destruíram. Atena, em Erecteu, representa a ajuda de Posêidon ao exército inimigo como uma tentativa de aniquilar sua cidade amada, ${ }^{45}$ situação revertida ao instaurar o culto de Posêidon-Erecteu, o que dialoga com a realidade cultual dos espectadores, já que Posêidon também é um dos deuses tutelares da cidade. ${ }^{46}$

Erecteu deve ter sido apresentada na década de 420, sendo 423 ou 422 as datas mais aceitas, ${ }^{47}$ portanto, não muitos anos antes de Troianas, época - a da Guerra Arquidâmia - em que mitos atenienses foram representados nas Grandes Dionísias, pelo menos por Eurípides, de uma forma que, no mínimo, não parece ser tão patriótica como aquela que adquirem na oração fúnebre. ${ }^{48} \mathrm{Em}$ vista disso e do que foi defendido até aqui, proponho que o

43 Cf. Collard, Cropp \& Lee 1995: 149, e Sonnino 2010: 213-14.

44 Calame 2011 insiste nos dêiticos usados nessa tragédia, indicadores de que o público ateniense participa da cerimônia ritual que é o próprio espetáculo trágico.

45 "Proclamo que afastes teu tridente desta região, / senhor Posêidon, não destruas minha terra / nem aniquiles minha cidade amada" (TrGF 370, 55-57 Kannicht).

46 Calame 2011 explora o reflexo da realidade cultual dos espectadores na tragédia.

47 Cf. Collard, Cropp \& Lee 1995: 155 e Sonnino 2010: 27-34.

48 Cf., por exemplo, a interpretação de Suplicantes por Pucci 2016: 95-141. 
prólogo de Troianas possa ter evocado para o público ateniense as formas do conflito entre Atena e Posêidon pela supremacia sobre Atenas. Uma delas é o mito apresentado em Erecteu, que, por sua vez, está atado a outra forma dessa disputa, a vitória de Atena sobre Posêidon por meio da primeira oliveira. ${ }^{49}$ O conjunto formado por esses dois mitos, por sua vez, articula-se nas duas principais construções da Acrópole, o Pártenon e o Erectêion, ${ }^{50}$ que foi construído, em sua maior parte, após a Paz de Nícias no final da década de $420.5^{51}$ O conjunto dos dois templos, de diversas maneiras, indica que a benevolência desses dois deuses para com Atenas está vinculada a grandes conflitos. Mais do que isso: tendo em vista a história dos diversos templos da Acrópole no século V e a confluência cultual entre o Pártenon e o Erectêion, não é impossível que os atenienses tenham decidido construir o templo mais novo com receio de que a cidade não estivesse devidamente protegida, ou seja, de que não tivesse honrado seus deuses principais da forma mais correta. ${ }^{2}$

O mito da disputa entre Posêidon e Atena parece ter-se tornado onipresente na cultura ateniense. Seu uso no Menêxeno de Platão sugere que não tenha sido um tópico pouco recorrente na oração fúnebre. ${ }^{53}$ Trata-se de uma passagem no início do discurso de Aspásia, logo após o louvor da linhagem ateniense e de sua autoctonia: "Essa região é digna de ser louvada por todos os homens, não somente por nós, e por muitas e diversas razões, mas primeira e principalmente porque é amada pelos deuses

49 Acerca da dificuldade de reconstruirmos a arqueologia dos elementos desse mito, cf. Parker 1987: 196-200.

50 Os dois templos albergavam uma estátua de Atena.

51 Cf. Hurwit 2004: 173-74. O Erectêion foi construído para ser a sede da mais reverenciada estátua de Atena, o to arkhaion agalma; cf. Shear 2016: 360-61. Shear 2016: 373-76 defende que Erecteu contém uma etiologia para a construção do Erectêion, que não deve ter sido decidida muitos anos antes de 423/2, a provável data da tragédia.

52 A especulação é um "learned guess" de Shear 2016: 370-75, o qual me parece convincente em vista das contingências em Atenas na década de 420 e por que os templos não parecem ser complementares. Diz Shear (p. 381): "Every detail of the Parthenon strove to achieve perfection in a temple for the goddess. And yet in the years following completion of its sculptures in 432, the city had experienced nothing but war and misery and catastrophic sickness, and finally violent earthquakes. It is in this context that the decision to build the Erechtheion becomes readily understandable".

53 Tsitsiridis 1998: 207-8. 
(theophiles). ${ }^{54}$ Em favor do nosso discurso testemunha a querela (eris) dos deuses que a reivindicaram e a sua decisão (krisis). Portanto, aquela que os deuses louvaram, como não será justo que seja louvada por todos os homens?" (Pl. Mx. 237c-d). Repare-se que a ênfase é toda na philia que os deuses sentem pela cidade (e não na cólera de Posêidon), uma perspectiva de se encarar os deuses recorrente em discursos políticos, judiciários e historiográficos, mas mais complexa na tragédia, quando é o outro lado - dos deuses encolerizados - que predomina. ${ }^{55}$

Em Troianas, o mito da dádiva da primeira oliveira é evocado no início do segundo estásimo, ${ }^{56}$ após a cena de despedida de Andrômaca e antes do agon entre Hécuba e Helena (Tr. 799-803):
Da apinutriz Salamina, ó rei Télamon, ocupando o trono da ilha envolta em ondas que se reclina face às sacras escarpas, onde Atena glauca mostrou o primeiro ramo da oliveira, celeste coroa e adorno à brilhosa (liparaisi) Atenas (...)

Esse canto trata, em paralelo, da primeira destruição de Troia, campanha da qual participou Héracles, e do amor dos deuses por alguns troianos Ganimedes e Titono -, que a princípio deveria funcionar como metonímia do amor pela cidade. Contudo, o amor por troianos individuais não impediu, como destaca o coro, a destruição final, representada no drama em andamento. Não me parece ser por acaso, portanto, que o amor da deusa Atena por Atenas abra a ode na qual a indiferença dos deuses, sob a perspectiva troiana, a fecha. No primeiro estásimo (Tr. 511-67), o coro narrou como o cavalo de pau foi recebido com festa e levado ao Pérgamo, a acrópole de Troia na qual se encontrava não só o palácio de Príamo, mas também

54 Acerca da relação desse adjetivo, particularmente frequente em fontes atenienses, e a crença de que uma cidade pode gozar da amizade dos deuses, cf. Tsitsiridis 1998: 205-6). Cf., à guisa de ilustração, o primeiro estásimo de Édipo em Colono.

55 Cf. Parker 1997 e 2005: 146-47. Pucci 2016 liga a cólera e outras emoções divinas com consequências funestas dos dramas de Eurípides a uma representação antropomorfizada dos deuses que é criticada pelo tragediógrafo.

56 A outra menção do mito em Eurípides é Íon 1433. 
o templo de Atena. No final do estásimo seguinte, o coro menciona a ruína do Pérgamo (Tr. 839-59):

Desejo (Eros), Desejo, que aos pavilhões dardaneus vieste

considerado pelos celestes,

quão magnífica torrergueste Troia, com os deuses

unindo em parentesco. Mas de Zeus

a crítica jamais farei:

o clarão da alvialada Manhã,

amável aos mortais,

viu o ruinoso à terra,

a ruína do Pérgamo viu,

pegando o faz-filhos desta

terra, esposo em bodas,

o qual o carro dourado estelar

com quatro cavalos tomou, raptando,

grande esperança à terra pátria. Mas os amavios

dos deuses partiram de Troia.

Desse modo, pode-se perguntar se essa ode convida o público ateniense a encarar sua relação com Atena como potencialmente finita ou, ao contrário, se ela reforça a continuada proteção de Atena sobre Atenas. Afinal de contas, Salamina, citada no início da ode, evoca o instante mais crítico da história de Atenas, mas que terminou com a vitória sobre os persas em 480/79.

Para falar da primeira destruição de Troia, o coro escolhe Télamon, o herói de Salamina, e não o dórico Héracles. Para elogiar Salamina, por outro lado, não se fala da própria região ou da linhagem de Télamon, como seria o caso em um epinício, ${ }^{57}$ mas de Atenas, ${ }^{58}$ introduzida por meio de sua relação simbiótica com Atena. Assim, Troia e Atenas, nesse estásimo, são, ao mesmo tempo, diferenciadas quanto à forma de seu elogio - Atena

57 O ramo de oliveira dado por Atena é uma coroa celeste e um adorno (kosmos); a referência à linguagem e aos temas dos epinícios é clara; cf. Biehl 1989: 305.

58 Repare no uso do adjetivo "brilhoso" (liparos), tradicional em discursos de elogio da cidade, de tal forma que pode ser usado satiricamente por Aristófanes (Olson 2002: 238). 
é referida como aquela que forneceu a oliveira, não como a deusa que participou de um pequeno drama erótico (como Zeus e Aurora), qual seja, o nascimento do primeiro rei de Atenas, Erictônio/Erecteu - e parcialmente aproximadas: em que pese o amor dos deuses, Troia está sendo destruída uma segunda vez; já Atenas, embora arrasada uma vez, foi salva, na sequência imediata, pela batalha que ocorreu junto à Salamina.59

Temáticas cívicas atenienses, ao longo do drama, por certo louvam a cidade da plateia, parecendo, no limite, bajulá-la (Tr. 208-19). Trata-se de algo recorrente nas tragédias e criticado por personagens de Aristófanes e Platão também em relação a outros discursos públicos, de sorte que devemos nos lembrar que a apresentação de uma tragédia faz parte de um concurso arraigado em práticas democráticas que, em última instância, celebram não somente Dioniso, mas também a cidade de Atenas. ${ }^{60}$ Por outro lado, essa temática não se encontra desvinculada das forças de destruição que se alastram pelo drama, por exemplo, na cena de Cassandra, que utiliza e subverte uma série de temas do epitaphios logos para elogiar Troia e a si mesma.61 Por conseguinte, não me parece claro que as óbvias diferenças entre a Atenas dos espectadores e a Troia da tragédia sejam suficientes para garantir ao público ateniense que esse, em plena Guerra do Pelopeneso, às vésperas do desastre da Sicília, encontra-se mais bem preparado que Troia para evitar, uma segunda vez, o destino funesto dessa cidade.

\section{Atenas no prólogo de TROIANas?}

Não é possível reconstituir até que ponto, em Erecteu, a dádiva da oliveira é contraposta à desgraça que os atenienses, sobretudo a família real, é obrigada a enfrentar, nem se e como o poderio naval contemporâneo da

59 Acerca da importância de Salamina no imaginário ateniense, cf. v. g. Pl. Mx. 240e-241c.

60 Acerca do caráter democrático de diversos festivais e de seus agônes em Atenas, cf. Osborne 2010: 325-40.

61 Cf. Werner 2002. Em Suplicantes e Erecteu, o epitaphios logos também subjaz a discursos que estão longe de ser puramente laudatórios, sobretudo se levada em conta a tragédia como um todo. Cf. Sonnino 2010: 36-41 e 110-18 e Pucci 2016: 130-35. 
cidade poderia ter sido evocado em vista do papel central ocupado por Posêidon na economia do drama. ${ }^{62}$ Não sabemos se o drama como um todo louvava a Atenas contemporânea do espetáculo. Ao se examinar o modo como Licurgo utiliza o discurso de Praxítea em Contra Leócrates, não se deve esquecer que se trata de uma época em que a herança trágica ateniense recebeu uma aguda flexão política em vista das consequências do conflito com a Macedônia. ${ }^{63}$ A própria forma como Atenas, no que diz respeito a seus mitos e também à sua história recente, é trabalhada por Eurípides em outros dois dramas supérstites dos anos 420, Suplicantes e Heraclidas, não favorece a leitura patriótica. Seja como for, os últimos versos de Erecteu sugerem algo positivo, particularmente a união entre Posêidon e Atena por meio da instituição do culto de Posêidon-Erecteu. ${ }^{64}$

Para essa discussão, pode-se trazer a passagem do prólogo de Troianas em que Atena busca transformar uma dissenção em uma aliança: "Pode-se com parente paterno mui próximo, / nume poderoso e honrado entre os deuses, / falar, depois de eu ter dissolvido o ódio antigo?" (Tr. 48-50). "Ódio antigo" (ekhthran ten paros) refere-se, dramaticamente, à briga "troiana" entre Posêidon e Atena, mencionada no início do monólogo do deus: o cavalo concebido por essa foi responsável pela destruição da muralha construída por aquele (Tr. 4-12). ${ }^{65}$ Posêidon é obrigado a deixar a cidade por ter sido vencido por Hera e Atena (Tr. 23-24). ${ }^{66}$

É no monólogo de Posêidon que se dá a primeira menção explícita de Atenas. O contraponto aos helenos vitoriosos são as cativas de guerra: "umas, a tropa árcade, outras, a tessália / e os Teseidas, chefes dos atenienses,

62 Para as possíveis relações entre o culto de Posêidon e o aumento do poderio naval de Atenas ao longo do século V, cf. Hurwit 2004: 44-45.

63 Eurípides em Contra Leócrates: Hanink 2013 e 2014 (sobretudo páginas 25 a 59).

64 Considero a defesa de Scullion 2000 do caráter "fictício" das etiologias presentes no final de diversas tragédias de Eurípides como tendo sido refutada, em boa medida, por trabalhos posteriores; para a bibliografia mais relevante e uma utilização de Erecteu nessa discussão, cf. Calame 2011: 16 (especialmente n. 49).

65 Cf. a repetição de purgoi nos versos 5 e 12. Importante lembrar a estreita associação entre Atena (e Posêidon) com cavalos, de sorte que o cavalo "is itself a major theme of the Parthenon sculptural program. Through it, the power of Athena Hippia (and, perhaps, her superiority to Poseidon Hippios) is made visible" (Hurwit 2004: 26-27).

$66 \mathrm{Na}$ representação da Guerra de Troia, quando apenas um deus é referido como responsável pela destruição da cidade, é comum esse deus ser Atena; cf. E. Andr. 1251-52. 
obtiveram" (Tr. 30-31). Não é possível se afirmar com certeza o que a menção desse trio provocaria na plateia da tragédia, mas o louvor de Atenas ${ }^{67}$ como participante da Guerra de Troia é óbvio, já que a cidade recebe um verso inteiro e a menção de seus chefes se dá por meio da alusão ao herói epicórico Teseu. Por outro lado, isso também coloca os atenienses que participaram da conquista como vítimas em potencial da vingança dos deuses que será negociada na sequência.

O monólogo de Posêidon termina com uma referência ao papel central de Atena na destruição de Troia, de sorte que a expressão "ódio antigo", usada por Atena logo depois, sugere o conflito entre os deuses durante a Guerra de Troia. Não me parece impossível, porém, que a plateia ateniense também pensasse na disputa central em seu imaginário, aquela em torno de sua própria cidade. ${ }^{68}$

Algo semelhante a esse possível arco ligando o conflito ateniense e o troiano também pode subjazer, se não na composição, pelo menos na recepção de um dos dois poemas homéricos já canônicos no século V, a Odisseia. Tendo em vista nossa ignorância acerca do processo de composição do poema, não há indícios suficientes que corroborem a tese ${ }^{69}$ segundo a qual mitos e ritos atenienses, especialmente o culto de Erecteu-Posêidon, foram fundamentais na forma adquirida pela Odisseia, poema no qual o deus tutelar do herói é Atena e seu antagonista, Posêidon. ${ }^{70}$ Isso não impede que se afirme que esse poema, canonizado pelos pisistrátidas no contexto das Panateneias e, em conjunto com a Ilíada, já nessa época ícones culturais em Atenas, tenha estado em permanente diálogo, em inúmeros momentos de sua recepção na cidade, com as formas dos mitos atenienses que tratam de seus deuses tutelares. ${ }^{71}$

67 Cf. Lee 1976: 70.

68 Não é necessário o tom categórico de Biehl 1989: 114, para quem a expressão remeteria de forma inequívoca ao conflito ateniense dos deuses.

69 Cf. Cook 1995.

70 Para uma crítica dessa interpretação da Odisseia, cf. Ford 1996.

71 Cf. Jensen 1980, que defende que os poemas homéricos foram ditados na época dos pisistrátidas. 
Em Troianas, a união buscada por Atena no diálogo com Posêidon seria, portanto, a chave épico-troiana de uma simbiose ideal do ponto de vista ateniense. Ela manifestou-se na transformação de Atenas, ao longo do século $\mathrm{V}$, em potência naval, ${ }^{72}$ e também está presente no final de Erecteu. Dessa forma, Posêidon, para a plateia de Troianas, não seria somente o deus que construiu os muros de Troia e amou essa cidade, mas também aquele que, a partir de certo momento, deixou de lado seu rancor contra os atenienses e beneficiou a cidade com seu poderio marítimo. A familiaridade do público do drama com o deus da Ilíada, rancoroso e destrutivo, ${ }^{73}$ faz dessa representação de Posêidon algo surpreendente, mas que é, ao mesmo tempo, embasada pela sua atuação nos mitos atenienses, nos quais passa de deus antagonista a tutelar.

A união entre Atena e Posêidon, porém, não ocorre para glorificar uma cidade, como no imaginário ateniense, mas para aniquilar quem destruiu Troia de uma forma ímpia. Também é fundamental que, se levarmos em conta o drama como um todo, os deuses deixam a cidade quando o prólogo termina para não mais voltarem - e deixam a cidade juntos. Nesse sentido, seria possível para o espectador ateniense pensar em sua própria cidade ao ver Troia abandonada em definitivo por seu deus políade?

Quando Posêidon se despede de Troia, ele menciona Atena em conexão

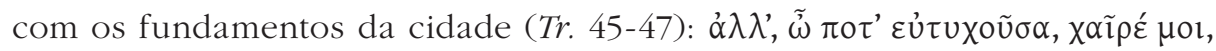

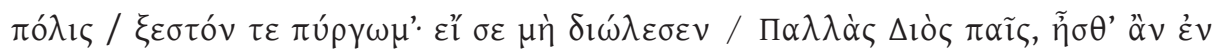

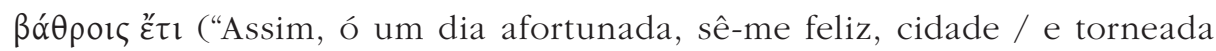
muralha: se não te tivesse aniquilado / Palas, filha de Zeus, ainda estarias em teus fundamentos"). Diversos paralelos podem ser traçados entre esses versos e o início da elegia $4 \mathrm{~W}$. de Sólon, de dicção fortemente homérica: ${ }^{74}$

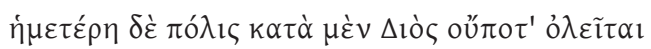

72 Parker 1987 discute o modo como as formas do mito que trata do conflito entre Posêidon e Atena, que remete a um esquema tradicional no qual o deus perdedor costuma hostilizar a cidade que o preteriu, podem ou não estar ligadas à supremacia naval crescente de Atenas a partir de 470.

73 Cf., por exemplo, Hom. Il. 15. 184-217 (resposta de Posêidon à ordem de Zeus transmitida por Íris).

74 Para uma discussão da dicção dessa elegia, cf. Irwin 2005: 91. 


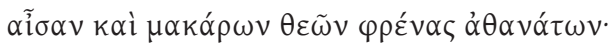

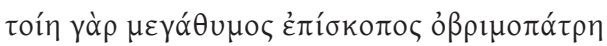

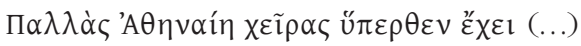

Sim, nossa cidade nunca perecerá de acordo com o quinhão advindo de Zeus e o juízo de venturosos deuses imortais, pois uma tal animosa guardiã, a pai-poderoso, Palas Atena, sobre ela mantém as mãos (...)

Os paralelos lexicais e semânticos não são suficientes para demonstrar ou mesmo sugerir que Eurípides e seu público teriam o trecho elegíaco em mente, pois a natureza desses paralelos é algo genérica. É inegável, porém, que as duas construções evocam o tema tradicional da destruição de uma cidade por um deus ${ }^{75}$ e, em particular, a relação de Atena com a fortuna de uma cidade. Assim, os versos de Eurípides funcionam como preparação para a sequência do prólogo, quando Atena se mostra uma típica deusa da épica homérica, uma divindade que, por motivações pessoais, abre mão de uma cidade, ainda que essa seja muito amada (no caso, uma coletividade, os aqueus). Nesse sentido, quanto mais forte for a ligação, para o espectador de Troianas, entre o modo como os deuses agem no drama e sua presença no imaginário ateniense, mais claro é o alerta que subjaz ao enredo: não se pode confiar, da forma categórica e irrestrita, que Atenas será para sempre protegida por seu principal deus tutelar, o que também parece ser afirmado no trecho de Sólon. ${ }^{76}$ Todavia, Atena mostra a Posêidon que, assim como na sequência da elegia de Sólon, são os próprios gregos que trouxeram a desgraça para si mesmos; ou seja, se está diante de uma ideia moral

75 Cf. Ilíada 4 (as cidades de Hera) e 6 (Atena não atende o pedido de sua sacerdotisa troiana), Odisseia 13 (a possível destruição da cidade dos feácios por Posêidon) e a discussão dessa temática em Irwin 2005: 92.

76 A forma mais comum de ler o trecho de Sólon é que Atena contrabalança, no mundo divino, eventuais ameaças de outros deuses (Irwin 2005: 92-94); cf., porém, Blaise 2006: 125-26. 
comum no imaginário grego, a de que os deuses não tendem a reagir de forma arbitrária. ${ }^{77}$

O prólogo fala de um conflito entre Posêidon e Atena em torno de uma cidade, Troia, vencido, primeiro, por Atena por meio do cavalo de pau e depois transformado em uma união, a de Atena com Posêidon contra os gregos. O vocabulário religioso empregado por Posêidon implica, para o espectador, uma relação geral dos dois deuses com seus respectivos templos, ou seja, não necessariamente aqueles que se encontram na Acrópole ateniense. Assim uma equiparação entre Troia e Atenas ou entre os gregos e os atenienses é deixada para o espectador, inclusive porque Atenas pode, a princípio, servir de paralelo tanto para Troia como para a frota grega. O convite do espetáculo a seus espectadores atenienses seria antes o de que pensassem sua cidade a partir de e não como Troia e/ou como o exército grego.

\section{CONCLUSÃo}

Posêidon foi derrotado em Troia pelas mesmas deusas, Hera e Atena, que, respectivamente, o venceram em Argos e Atenas. ${ }^{78}$ Desde o início de Troianas é definida a participação efetiva da esfera divina na destruição de Troia, sendo possível que Posêidon tenha sido escolhido por Eurípides como aliado dos troianos para acentuar o ódio de Atena e Hera como determinantes na destruição da cidade, indicando, dessa forma, a importância do julgamento de Páris no destino de Troia, tema retomado diversas vezes ao longo do drama, mas que também serve a uma crítica à representação antropomórfica, vale dizer, tradicional dos deuses. ${ }^{79}$ Assumindo-se esse viés, porém, a presença de Apolo, ao invés de Posêidon, não representaria uma grande

77 Cf., por exemplo, a sequência da elegia de Sólon, a fala de Zeus em Hom. Od. 1, 32-43 (cf. huper moron) e a contraposição da Cidade Justa e da Injusta em Hes. Op. 213-74.

78 Cf. Detienne \& Sissa 1990: 175-88.

79 Sobre o julgamento de Páris, cf. Scodel 1980: 65 e Erbse 1984: 63. Acerca da representação mítica dos deuses em Troianas, sobretudo no debate entre Hécuba e Helena, cf. Pucci 2016: 4-14 e 34-42. 
diferença e seria muito bem motivada, entre outras razões, por sua relação com Cassandra, explorada na sequência do drama. O conflito entre Atena e Posêidon, por outro lado, é tipicamente ateniense mais que pan-helênico.

Dessa forma, podemos concluir que as relações entre o universo de Troianas e o imaginário ateniense, embora não sejam necessárias, são, no mínimo, fortes e constantes o suficiente ao longo da tragédia como um todo para terem determinado uma recepção plural do drama por parte de uma plateia que, justamente em vista das práticas democráticas cotidianas, sobretudo aquelas que permitiam e fomentavam o embate entre políticas distintas (por exemplo, na assembleia), estava acostumada a buscar uma visão de sua cidade que não seria sempre inequivocamente singular. A ausência dos deuses da cidade, acentuada ao longo do drama, e a forma como nele se constroem discursos e se tomam decisões, pode sugerir ao público que, para lidar com catástrofes, vale mais a pena basear-se na exploração da realidade por meio da palavra do que na confiança nos deuses.

Por fim, em que pese o estado fragmentário de Erecteu, algo semelhante pode ser sugerido também para essa tragédia: seguir-se às cegas o que prescrevem os deuses pode ser tão inócuo como introjetar uma versão apaixonada da ideologia cívica. Em vista dos fragmentos transmitidos, porém, não sabemos como se desenvolvem os discursos humanos no entorno da decisão de Praxítea e antes das proclamações finais de Atena.

\section{REFERÊNCIAS BIBLIOGRÁFICAS}

Allan, W. (2000), The Andromache and Euripidean Tragedy. Oxford.

. (2014), "Epic Heroes in Tragedy: Genre, Ethics, and the Fifth-century Community", in C. Werner; B. Sebastiani; A. O. Dourado-Lopes (eds.), Gêneros poéticos na Grécia Antiga: fronteiras e confluências. São Paulo, 99-124.

Allan, W.; Kelly, A. (2013), "Listening to Many Voices: Greek Tragedy as Popular Art", in A. Marmodoro; J. Hill (eds.), The Author's Voice in Classical and Late Antiquity. Oxford, 77-122. Biehl, W. (1989), Euripides: Troades. Heidelberg.

Blaise, F. (2006), "Poetics and Politics: Tradition Re-worked in Solon's 'Eunomia' (Poem 4)", in J. Blok; A. P. M. H. Lardinois (eds.), Solon of Athens: New Historical and Philological Approaches. 
Leiden, 114-33.

Bowie, A. M. (2012), "Mythology and the Expedition of Xerxes", in E. Baragwanath; M. de Bakker (eds.), Myth, Truth and Narrative in Herodotus. Oxford, 269-86.

Calame, C. (2011), "Myth and Performance on the Athenian Stage: Praxithea, Erechtheus, Their Daughters, and the Aetiology of Autochthony", CP 106, 1: 1-19.

Carter, D. M. (2007), The Politics of Greek Tragedy. Exeter.

Collard, C.; Cropp, M. J.; Lee, K. H. (1995), Euripides: Selected Fragmentary Plays. Vol. 1. Warminster. Conacher, D. J. (1967), Euripidean Drama: Myth, Theme and Structure. Toronto.

Connelly, J. B. (1996), "Parthenon and Parthenoi: a Mythological Interpretation of the Parthenon Frieze", AJA 100: 58-80.

. (2014), The Parthenon Enigma: a New Understanding of the West's Most Iconic Building and the People who Made It. New York.

Cook, E. F. (1995), The Odyssey in Athens: Myths of Cultural Origin. Ithaca/London.

Cropp, M. (2014), "Cropp on Queyrel on Connelly. Response to BMCR 2014.09.14", BMCR 2014.10.45.

Csapo, E.; Wilson, P. (2015), "Drama Outside Athens in the Fifth and Fourth Centuries B. C.", TC 7, 2: 316-95.

Detienne, M.; Sissa, G. (1990), Os deuses gregos. São Paulo.

Diggle, J. (1981), Euripidis Fabulae, vol. 2. Oxford.

Dunn, F. M. (1993), "Beginning at the End in Euripides Trojan Women", RMPh 136: 22-35.

Erbse, H. (1984), Studium zum Prolog des euripideischen Tragödie. Berlin.

Ferrari, G. (2000), "The Iliupersis in Athens", HSCP 100: 119-50.

Fontenrose, J. (1967), "Poseidon in the Troades", Agon 1: 135-141.

Ford, A. (1996), "Ford on Cook 1995". BMCR 27/04/1996.

Hanink, J. (2013), "Epitaphioi mythoi and Tragedy as Encomium of Athens", TC 5, 2: 289-317. . (2014), Lycurgan Athens and the Making of Classical Tragedy. Cambridge.

Harder, R. E. (1993), Die Frauenrollen bei Euripides: Untersuchungen zu Alkestis, Medeia, Hekabe, Erechteus, Elektra, Troades und Iphigenia in Aulis. Stuttgart.

Hurwitt, J. (2004), The Acropolis in the Age of Pericles. Cambridge.

Irwin, E. (2005), Solon and Early Greek Poetry: the Politics of Exortation. Cambridge.

Jensen, M. S. (1980), The Homeric Question and the Oral-Formulaic Theory. Copenhagen.

Kamerbeek, J. C. (1991), "En relisant les fragments de l'Eréchthée d'Euripide", in H. Hofmann; A. Harder, A. (eds.), Fragmenta dramatica. Göttingen, 111-16.

Kovacs, D. (1983), Euripides, Troades 95-7: is Sacking Cities Really Foolish? CQ 33: 334-38. . (1997), "Gods and Men in Euripides' Trojan Trilogy", Colby Quarterly 33: 162-76.

Lee, K. H. (1976), Euripides: Troades. Basingstoke; London.

Lefkowitz, M. R. (1989), “Impiety' and 'Atheism' in Euripides' Dramas”, CQ 39: 70-82.

Lloyd, M. A. (2007), "Euripides", in I. J. F. de Jong; R. Nünlist (eds.), Time in Ancient Greek Narrative. Leiden, 293-304.

. (2009), "The Language of the Gods: Politeness in the Prologue of the Troades", in J. R. C. Cousland; J. R. Hume (eds.), The Plays of Texts and Fragments: Essays in Honour of Martin Cropp. Leiden, 183-92.

Loraux, N. (1999), La voix endeuillée: essai sur la tragédie grecque. Paris.

Olson, S. D. (2002), Aristophanes Acharnians: Edited with Introduction and Commentary. Oxford.

Osborne, R. (2010), Athens and the Athenian Democracy. Cambridge. . (2013), "Democracy and Religion in Classical Greece", in J. P. Arnason; K. A. Raaflaub; P. Wagner (eds.), The Greek polis and the Invention of Democracy: a Politico-Cultural 
Transformation and its Interpretations. Malden/MA, 274-97.

Parker, L. P. E. (2007), Euripides Alcestis. With Introduction E Commentary. Oxford.

Parker, R. (1987), "Myths of early Athens", in J. N. Bremer (ed.), Interpretations of Greek Mythology. London, 187-214.

. (1997), "Gods Cruel and Kind: Tragic and Civic Theology", in C. Pelling (ed.), Greek Tragedy and the Historian. Oxford, 143-60.

. (2005), Polytheism and Society at Athens. Oxford.

Poole, A. (1976), "Total Disaster: Euripides' The Trojan Women", Arion 3: 257-87.

Pucci, P. (2016), Euripides' Revolution under Cover: an Essay. Cornell.

Richardson, N. J. (1974), The Homeric Hymn to Demeter. Oxford.

Roselli, D. (2011), Theater of the People: Spectators and Society in Ancient Athens. Austin.

Scodel, R. (1980), The Trojan Trilogy of Euripides. Göttingen.

Scullion, S. (2000), "Tradition and Invention in Euripidean Aitiology", ICS 24-25: 217-33.

Shear JR., T. L. (2016), Trophies of Victory: Public Building in Periklean Athens. Princeton.

Sonnino, M. (2010), Euripidis Erechthei quae exstant. Firenze.

Sourvinou-Inwood, C. (2003), Tragedy and Athenian Religion. Lanham.

Silva, M. F. (2005), Ensaios sobre Euripides. Lisboa.

$\operatorname{Tr} G F=$ Kannicht, R. (ed.) (2004), Tragicorum graecorum fragmenta. Vol. 5: Euripides. Göttingen.

Tsitsiridis, S. (1998). Platons Menexenos: Einleitung, Text und Kommentar. Leipzig/Stuttgart.

Werner, C. (2002), "As performances de Cassandra em Troianas de Eurípides", Letras clássicas 6: 117-34.

. (2004), Eurípides: duas tragédias gregas. Hécuba e Troianas. São Paulo.

. (2011), "Troianas: do filme de Michael Cacoyannis à tragédia de Eurípides", Archai: 7: 131-36.

Wilson, J. R. (1968), "Poseidon in the Troades: a reply", Agon 2: 69-71.

Worthington, I.; Cooper, C. R.; Harris, E. M. (2001), Dinarchus, Hyperides, and Lycurgus. Austin. 